\title{
POSCOSECHA DE CAFÉ. FERMENTACIÓN Y SECADO SOLAR DE CAFÉ PERGAMINO EN FINCAS DE PEQUEÑOS PRODUCTORES DE SAN RAFAEL DEL NORTE, NICARAGUA
}

Luis María Dicovskiy Riobóo

Maestro en Estadística e Investigación

Sub director UNI-Norte

luisdi@norte.uni.edu.ni

\section{RESUMEN}

En el Municipio de San Rafael del Norte a 1,006, 1,115, 1,154 1,174 y 1,183 msnm a una latitud N de $13^{\circ}$ en dos cosechas 2007-2008 y 2008-2009 se evaluó una propuesta de mejora del fermentado y otra sobre el secado en finca del café pergamino. Con el objetivo de identificar puntos críticos en el proceso de fermentado y su relación con la calidad de taza, se estudió el proceso del fermentado tal como ocurre en la finca de productores. Las variables evaluadas en las pilas de fermentación fueron $\mathrm{pH}$, temperatura del café despulpado y calidad de taza. Se encontró que los tiempos de fermentación ideales del café despulpado para llegar a un $\mathrm{pH}$ de 4 - 4.5, son menores a lo que se usa tradicionalmente, pudiéndose sugerir que el productor debería, en general, lavar antes de lo que se está haciendo hoy día. Para garantizar un proceso de oreado rápido del café pergamino recién lavado, se evaluó un secador solar, éste consistió en una estructura de tubo de hierro galvanizado recubierta de plástico translúcido, con un área útil de secado de $18 \mathrm{~m}^{2}$ y una capacidad para $160 \mathrm{Kg}$ de café pergamino. En los dos ciclos evaluados, en el secador se obtuvo una temperatura media superior en $8^{\circ} \mathrm{C}$ respecto a la temperatura ambiente, lográndose reducir el período de oreado de los granos de café en un 50\%. Debido a la mejora de la calidad del café se estima conservadoramente que se pueden lograr unos 150 US\$ de ganancia por secador y por ciclo de cosecha.

Palabras claves: Fermentado, secador solar, café pergamino, micelio.

\section{INTRODUCCION}

En Nicaragua, tradicionalmente el café despulpado se fermenta con agua y luego se lava, proceso conocido como tipo Matagalpa. Si este proceso se hace bien se puede obtener un producto de muy buena calidad. Existen en Nicaragua más de 15,000 beneficios húmedos, instalados en las fincas cafetaleras en los departamentos de Matagalpa, Jinotega, Madriz, Nueva Segovia y Estelí donde se fermenta café. (InfoAgro, 2006 y Multiconsult, 2005).

La mala fermentación del café está asociada con defectos en el sabor. En el café tostado aparecen sabores a alcohol, a frutas, a flores y ácido y es uno de los problemas que afecta la calidad del café. La sub fermentación también plantea un riesgo, dado que las trazas del mucílago restante adherido a los granos pueden promover que se echen a perder los granos durante el secado y almacenamiento, cuando el $\mathrm{pH}$ está entre 4.6 - 4.0 se debe terminar la fermentación lavando con agua (Jackels, 2005).

Luego del proceso de fermentado y lavado, donde se extrae el mucílago que rodea el grano de café, el contenido de humedad del café pergamino está entre el $60 \%$ y el $55 \%$ del peso total. En la finca el grano se orea hasta un $40 \%$ de humedad y luego se manda a los beneficios secos para ser secado hasta un $12 \%$ de humedad, para que el grano de café luego pueda ser embodegado. Oreado con más del $42 \%$ de humedad y más de dos días ensacados se generan hongos en los granos, hay olor a tierra y se mira micelio en las ranuras del pergamino, el grano se pone mohoso y el daño es irreversible en la taza. Los granos húmedos constituyen un me- 
dio ideal para el desarrollo de microorganismos que dañan al producto y deterioran su aspecto. Los granos húmedos de café rápidamente se contaminan con ocratoxinas, micotoxinas producidas por hongos saprófitos de los géneros Aspergillus y Penicillium, las cuales son sustancias naturales muy tóxicas por su acción contra las células renales (Rodriguez, 2006).

A nivel de finca se pueden usar secadores solares con cobertores de plástico translúcido que se adaptan a las necesidades, incluso de los productores más pequeños. Estas estructuras en forma de túneles o pequeñas casas, permitirían al pequeño productor tener más tiempo el café en su finca, mientras cosecha el volumen necesario para llevarlo al beneficio (CDA, 2002)

El principio de uso de estos secadores es que al calentarse el aire, éste aumenta de volumen y, por lo tanto, disminuyen su densidad y ascienden desplazando el fluido que se encuentra en la parte superior y que está a menor temperatura, esto genera una corriente de aire caliente que actúa secando el grano.

Para mejorar un punto crítico de la calidad del café, como es el secado del mismo, se diseñó y evaluó una estructura con tubos y plástico transparente que actúa como secador solar, que permitió en la finca de productores del Municipio de San Rafael del Norte, orear rápidamente el café pergamino húmedo.

\section{METODOLOGÍA}

Con fondos de FUNICA y con la colaboración en campo de los estudiantes de la UNI Norte, Cristhiam Triminio Valenzuela, Julio Castellón López y Walter Espinoza Vanegas se montaron ensayos de fermentación y secado de café en 4 fincas de San Rafael del Norte a, 1,006, 1,115, 1,154 1,174 y $1,183 \mathrm{msnm}$ a una latitud $\mathrm{N}$ de $13^{\circ}$ en dos cosechas 2007-2008 y 2008-2009.

Se midió tiempos de fermentación de café pergamino despulpado con agua, siguiendo la forma de fermentación tradicional de los productores. Las fermentaciones ocurrieron de noche en pilas de cemento. El café fue despulpado con agua y luego fermentado. Se midió el $\mathrm{pH}$ hasta que los productores lavaran según su costumbre. En general se inició a fermentar por las tardes, luego que el productor recibía el café de los cortadores.

Las variables evaluadas en las pilas de fermentación fueron $\mathrm{pH}$ y temperatura del café despulpado, midiéndose el $\mathrm{pH}$ con peachímetros digitales manuales y la temperatura con termómetros de penetración, estas variables se midieron dentro de la pila de fermentación. También se tomaron 6 muestras que se llevaron a catación, tres a $\mathrm{pH}$ ideal para lavado y tres muestras al pH que lavó el productor.

Se diseñaron tres prototipos semejantes de un secador solar para café para ser usado en pequeñas fincas cafetaleras. El secador consistió en una estructura de 3 arcos de tubo de hierro galvanizado de 6.15 metros de alto, 3.20 metros de ancho y 2.10 metros de largo, todo unido por largueros. El área útil de secado era de $18 \mathrm{~m}^{2}$. Esta estructura se forró con plástico traslúcido comercial unido con sellador adhesivo. Este plástico permite el paso de los rayos solares pero retiene calor, el piso se forró con plástico negro para generar más calor. El costo de la estructura metálica del secador fue de 330 US\$ y se gastó unos 100 US\$ en el armado con plástico y alambre, para un valor aproximado de 430 US\$ por unidad de secado de $18 \mathrm{~m}^{2}$.

El prototipo uno tenía una puerta, dos aberturas rectangulares inferiores de circulación de aire al frente y una abertura rectangular de salida en la parte posterior superior. Para que circule el aire al prototipo dos se le adaptó aberturas móviles en el frente y una chimenea de pvc al fondo, se mantuvo la puerta. Al prototipo tres, aparte de lo anterior se le construyó una ventana móvil lateral para remover los granos sin necesidad de entrar al secador cuando la temperatura dentro de éste era alta. 
En el primer año de evaluación, se colocaron los granos de café en pisos dobles y simples de madera y cedazo para oreado, en el segundo año sólo se usaron pisos simples de cedazo, sistema que se observó era más efectivo.

El secador, prototipo uno y dos se evaluó en la cosecha 2007-2008 y en el ciclo 2008-2009 el secador prototipo tres. Cómo testigo se usó el grano oreado al ambiente en cajillas.

Durante el ciclo 2007-2008 las variables medidas en el secador y en el ambiente fueron: humedad relativa, temperatura en grados Celsius y pérdida de peso del café. En el 2008-2009 también se midió velocidad del viento a la entrada y a la salida del secador en $\mathrm{m} / \mathrm{s}$ (metros por segundo).

Los datos fueron sometidos a análisis de regresión lineal y no lineal con el programa SPSS.

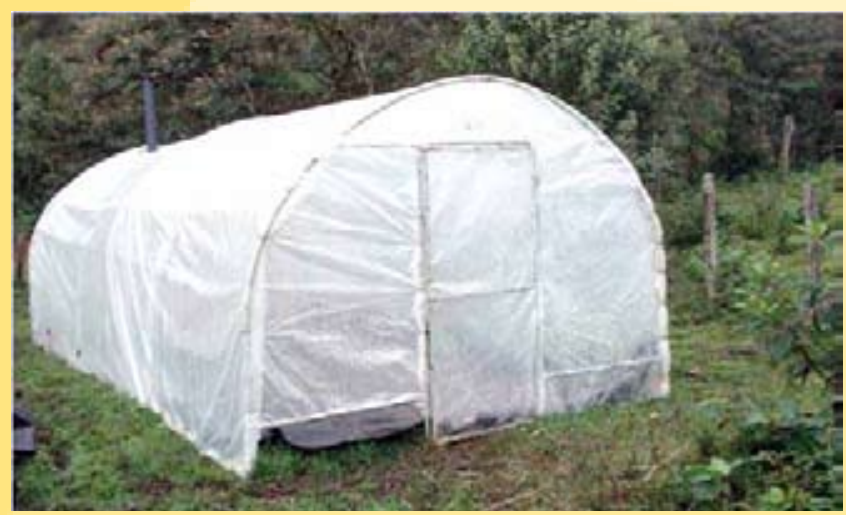

Vista frontal del secador

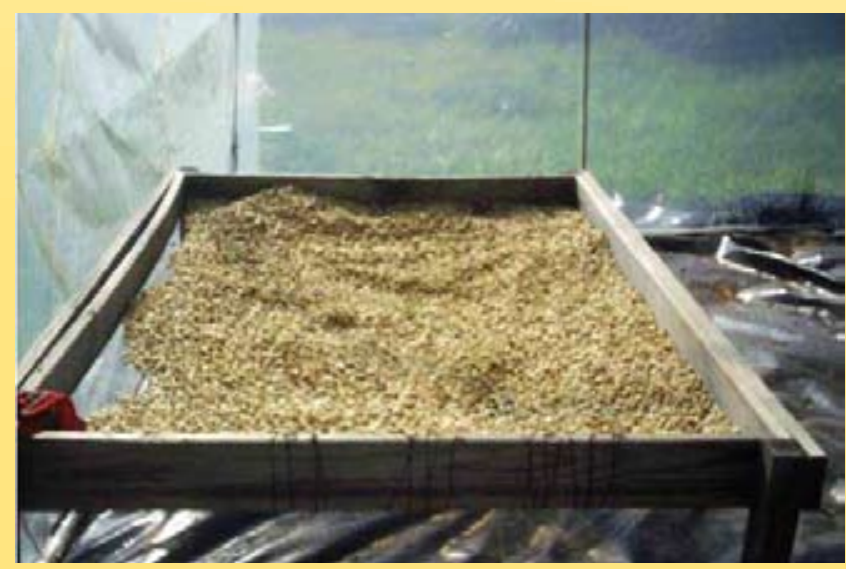

Interior del secador, piso de plástico negro, café en cajillas

\section{RESULTADOS}

Se encontró una regresión no lineal entre las temperaturas dentro de la pila y la hora de fermentación, el R2 fue de $0.188, \mathrm{p}=0.000$, donde . Se observó que en las primeras 15 horas hubo un leve aumento de temperatura y luego esta tiende a descender. Este aumento coincidió con el descenso de pH del café con mucilago.

La fermentación del café en las Segovias de Nicaragua se hace con un promedio de 18 horas, $\mathrm{y}$ las frecuencias de horas más comunes son 12 horas $(27 \%)$ y 24 horas $(22 \%)$ y el tiempo de fluctuación del $\mathrm{pH}$ en las pilas de fermentado puede variar por azúcares en el grano, altura de la masa de café en las pilas, dureza, tiempo entre corte y despulpado, etc. (Dicovskiy, 2009). En esta investigación al estudiar las fluctuaciones de $\mathrm{pH}$ se encontró una alta correlación, rPearson $=0.83$, $\mathrm{p}=0.000$, entre el $\mathrm{pH}$ del café con mucilago y el número de horas de iniciado el fermentado, ambas variables medidas dentro de la pila. Es de resaltar que el pH óptimo para despulpar de 4.6 - 4.00, (Jackels, 2005), se obtuvo según regresión lineal, entre las 9 y 12 horas de iniciado el fermentado. E1 R2 de la regresión fue de 0.601 y la ecuación. Ver gráfico 1.

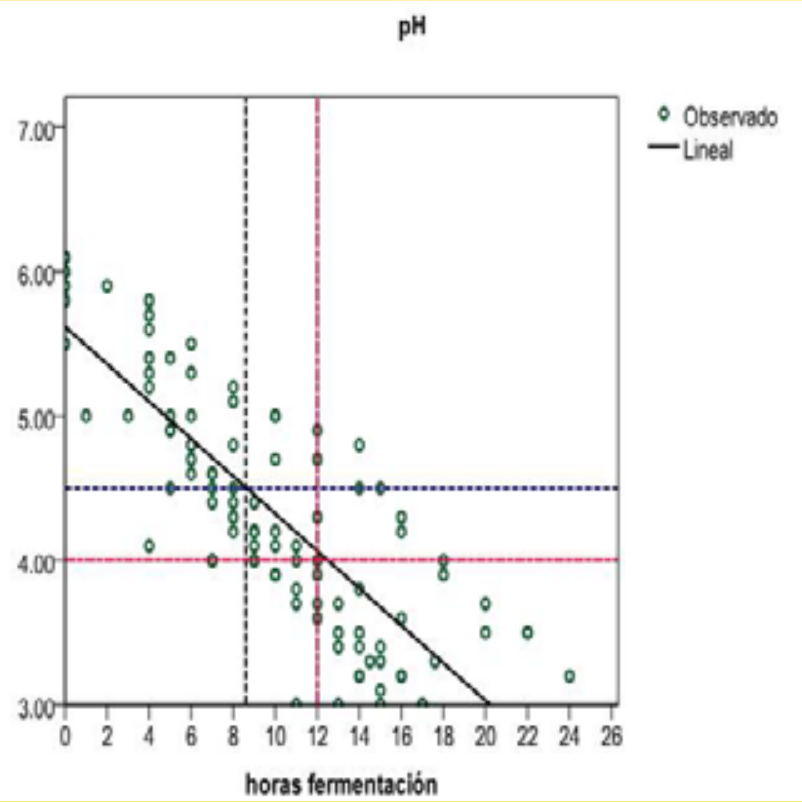

Gráfico 1: Horas de fermentación y variación de pH 
En el secador por gradiente térmico, se generaba una circulación de aire, entraba el aire frío por la parte inferior de la cara frontal, se calentaba en el secador y salía por la chimenea de la parte posterior superior por convección natural. Al entrar el aire más caliente en contacto con el grano húmedo, éste actuaba como secador. El secador tuvo en general entre 5 y 7 horas efectivo de oreado al día, de 9 am a 4 pm y demostró tener una capacidad de secar $3.5 \mathrm{qq}(159.9 \mathrm{Kg})$, si se usan 6 cajillas sencillas con capacidad de 55 libras (24.97 $\mathrm{kg}$ ) cada una de café pergamino húmedo.

\section{Temperaturas en San Rafael}

Se lograron obtener gradientes de temperatura hasta de $24.5^{\circ} \mathrm{C}$ en comparación con la temperatura del ambiente, pero de promedio se tuvo en el secador $8^{\circ} \mathrm{C}$ más que en el ambiente. En el secador se encontró una regresión no lineal, del tipo cuadrática, entre las hora del día, (de 7 am a 5 pm), y la temperatura alcanzada, de la forma , R2 0.471y $p=0.000$. Las mayores temperaturas se lograron a la $1 \mathrm{pm}$. Ver gráficos 2 y 3 . En el ciclo 2008-2009 se observó que si se orientaba mal la entrada de aire del secador éste no secaba mejor que el ambiente, esto se corrigió orientando la entrada de aire, la puerta, en la dirección predominante del viento.

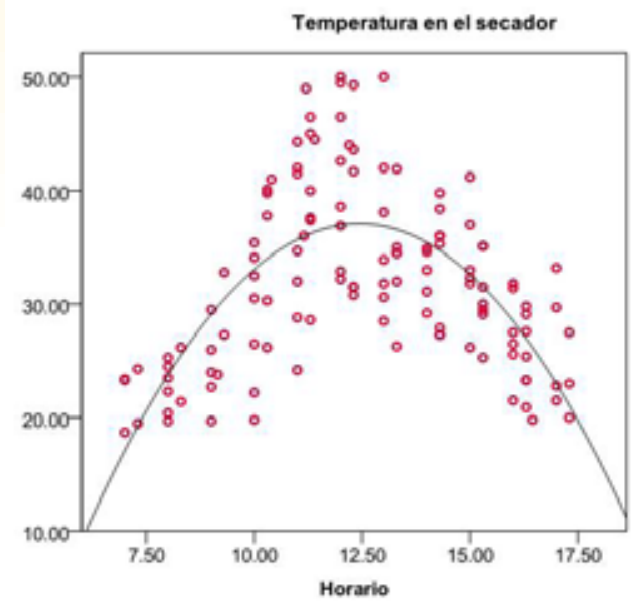

- Observado - Cuadrático

Horario

Gráfico 2: Temperaturas en el secador

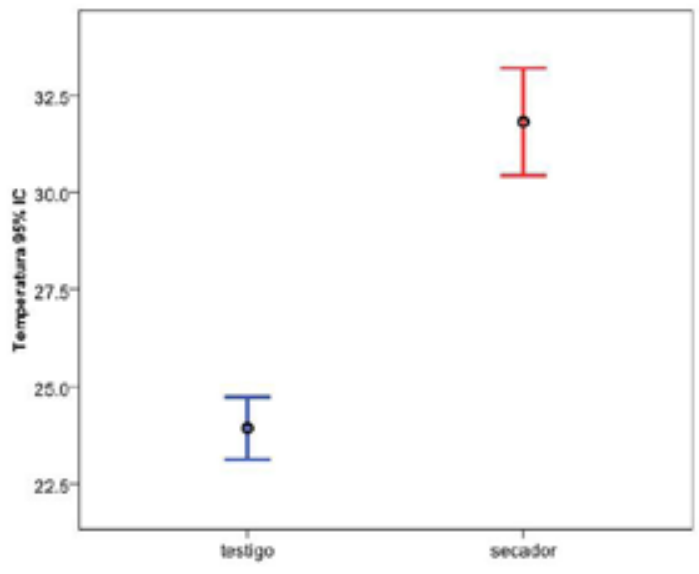

Gráfico 3: Intervalos de confianza de temperatura del Secador y el ambiente.

\section{Temperatura y humedad relativa}

Como era de esperar se encontró dentro del secador una correlación negativa y significativa entre la temperatura y la HR, de $\mathrm{r}_{\text {Pearson }}=-0.645, \mathrm{p}=0.000$, lo que indica que al calentarse el aire disminuía la HR mejorando así la acción de secado del aire sobre los granos húmedos. Ver gráfico 4 .

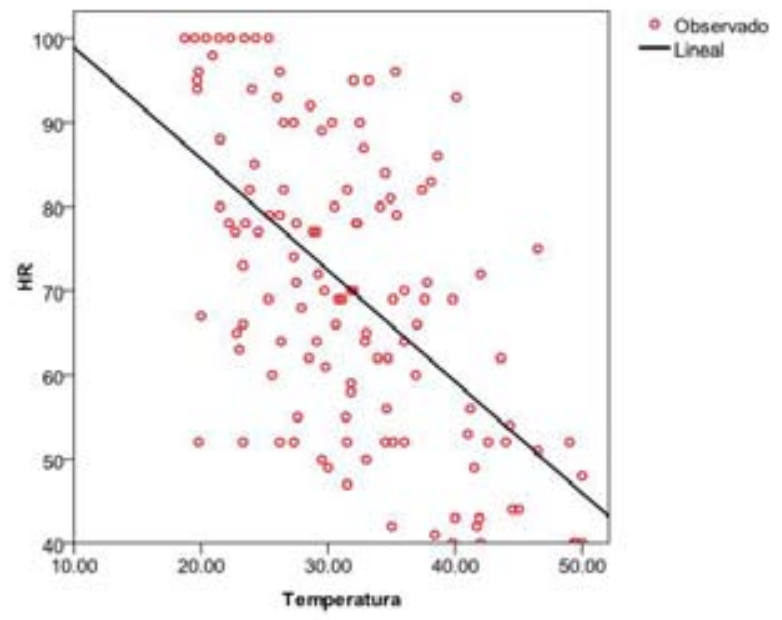

Gráfico 4. Regresión lineal entre temperatura y HR dentro del secador.

\section{Circulación del aire.}

La velocidad del aire a la salida del secador fue mayor que la velocidad del aire de la entrada de $1.21 \mathrm{~m} / \mathrm{s}(3.5 \mathrm{~m} / \mathrm{s}$ y $2.29 \mathrm{~m} / \mathrm{s}$ respectivamente $)$. Se encontró una correlación alta entre el aire en la 
entrada y a la salida del secador de rearson $=084$, $\mathrm{p}=0.000$, lo que nos dice que si el aire entra rápido también sale rápido, pero a mayor velocidad, probablemente por efecto de la convección térmica. Se encontró una correlación positiva muy baja, pero significativa entre la velocidad del aire cerca de la salida por la chimenea y la temperatura dentro del secador de $\mathrm{r}_{\text {Pearson }}=0.23, \mathrm{p}=0.043$.

\section{Pérdida de peso.}

Hubo una alta correlación significativa de $\mathrm{r}_{\text {Pearson }}=$ $0.83, \mathrm{p}=0.000$, entre la variable pérdida de peso del café pergamino húmedo y las horas del mismo en el secador, la regresión lineal entra estas dos variables quedó de la siguiente forma . En el secador, en 5 horas, un día efectivo de oreado, se logró reducir de promedio un 15\% la humedad del grano húmedo, pasando a café oreado, listo para ser llevado al beneficiado seco (con aproximadamente un $40 \%$ de humedad del grano pergamino). A temperatura ambiente esta reducción de humedad se logró casi a las 10 horas de secado, dos días efectivos de secado y a veces tres, ya que generalmente por problemas de lluvias, o rocío en el mejor de los casos, se comienza a secar a las 9 - 10 am y se termina a las 2 - 3 de la tarde. Se debe considerar que el secador no tiene problemas si llueve. Ver los gráficos 5 y 6 .

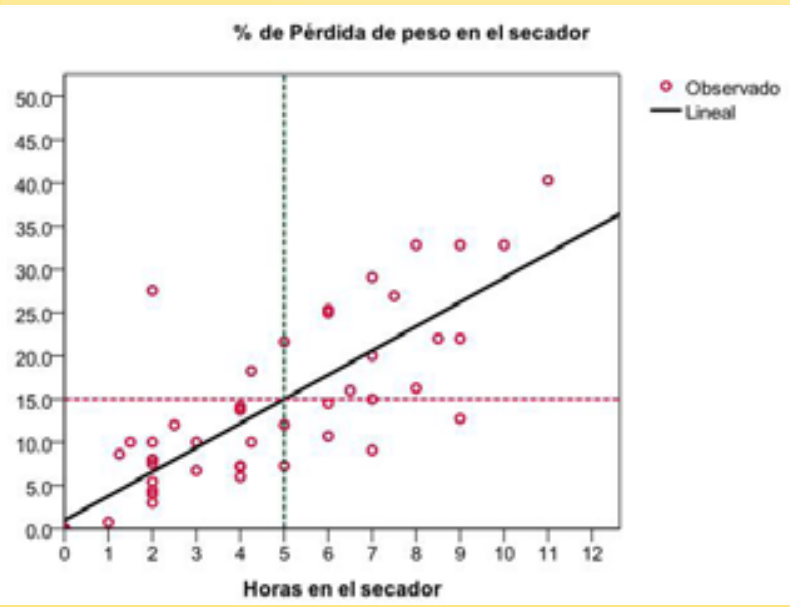

Gráfico 5: Pérdida de peso del café pergamino en el secador.

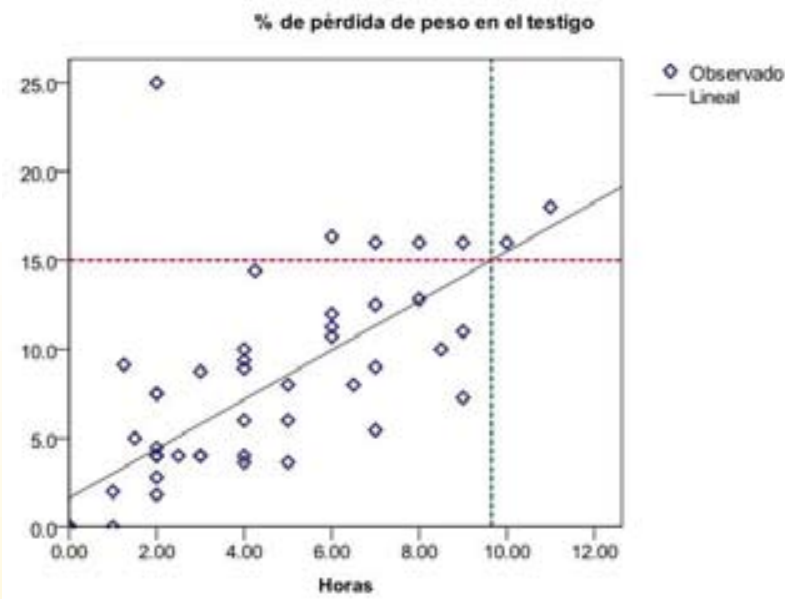

\section{Gráfico 6: Pérdida de peso del café pergamino a temperatura ambiente.}

\section{Calidad de catación en el secador}

Se realizaron cuatro pruebas de catación de muestras extraídas del secador y secadas en cajillas al ambiente y dieron resultados equivalentes de calidad en catación, 79 y 78 puntos respectivamente.

\section{Análisis económico del secador}

Costos. La estructura del secador cuesta aproximadamente 330 US\$, con una vida útil de al menos 5 años, el plástico y alambre para armar es estima en 100 US\$, material que puede durar dos años de uso.

La inversión anual es 66 US\$ por amortización de la estructura metálica y 50 US\$ por material plástico y alambre, para un total de inversión de 116 US\$ por ciclo de cosecha.

\section{Ahorros en uso del secador}

En 30 días efectivos el secador solar puede secar unos $105 \mathrm{qq}$ (4.77 Tn) de café pergamino, reduciéndose el tiempo de oreado en un 50\%, se ahorra de esta manera un $50 \%$ de la mano de obra en remover el grano, mientras éste se seca, aproximadamente 30 días hombre, unos 90 US\$ por ciclo de cosecha. 
Hay estimaciones que aproximadamente el 15\% del café que se cosecha, por efectos de sobre fermentación, mohos, café verde, etc. se clasifica como café de segunda, con una valor del $70 \%$ por debajo de café de primera, de exportación.

Se pierden así unos 36 US\$ por qq de café de segunda. Si estimamos conservadoramente, que 5 qq de los 105 qq que se pueden secar en una cosecha con el secador solar, pueden pasar de segunda a primera calidad, tenemos un ingreso extra por mejora de calidad de 180 US\$ por ciclo.

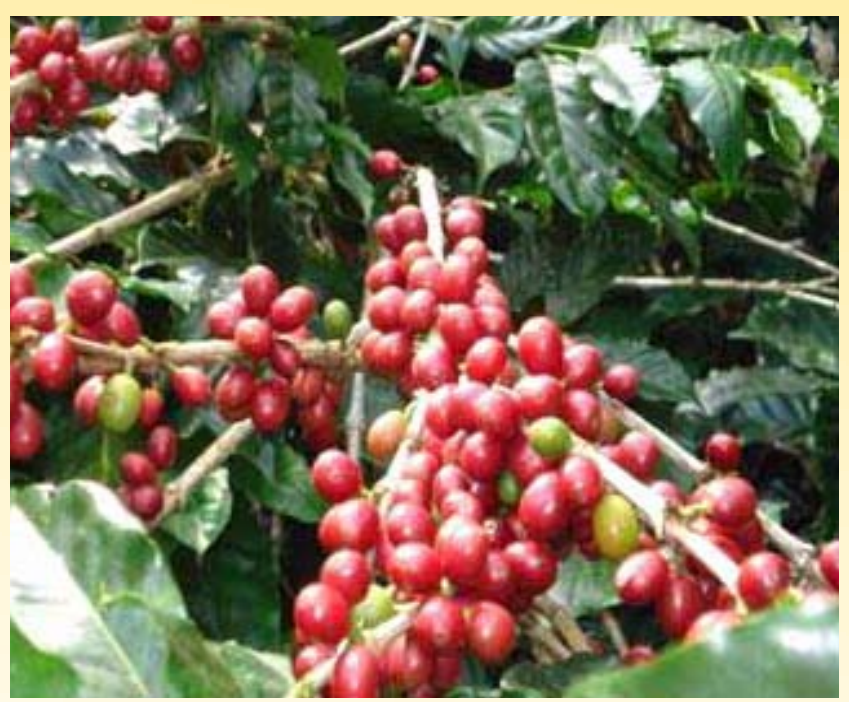

\section{CONCLUSIONES}

Se encontró en esta investigación que los tiempos de fermentación ideales del café despulpado para llegar a un $\mathrm{pH}$ de 4 - 4.5, son menores a lo que se usa tradicionalmente pudiéndose sugerir que el productor debería en general lavar antes de lo que está haciendo hoy día.

Se demostró que el secador solar en fincas situadas a más de 1,000 msnm logró un incremento promedio de temperatura de $8^{\circ} \mathrm{C}$ respecto al ambiente, lo que permite reducir el tiempo de oreado del café pergamino húmedo en un $50 \%$, respecto a la temperatura ambiente.

Para que el secador funcione bien la entrada de aire, la puerta del secador, debe estar orientada en la dirección del viento predominante.
Sólo con la reducción de la mano de obra por dejar de remover el grano mientras se seca, esta estructura casi paga sus costos, sin embargo debido a la mejora de la calidad del café se estima conservadoramente que se pueden lograr unos 150 US\$ de ganancia por ciclo de cosecha, al reducir el volumen de café de segunda calidad.

\section{BIBLIOGRAFÍA}

- CDA. (2002). Cafés Especiales. Honduras.

- Dicovskiy, L. (2009). Situación actual del cultivos de café en las Segovias, con énfasis en el estado de la cosecha en finca y la calidad. Nicaragua 2007-2008. El Higo, 5-9.

- InfoAgro. (2006). InfoAgro. Recuperado el 10 de Diciembre de 2006, de Http://www.infoagro.com/herbaceos/industriales/cafe.asp

- Jackels, S. (2005). Recuperado el 2009 de Mayo de 14, de Loyola: www.loyola.edu/Justice/documents/commitment2005/panel3 jackels.doc

- Multiconsult. (2005). Estudios de Ramas Industriales, Rama Café. Managua: FPP MARENA.

- Rodriguez, J. (11 de Octubre de 2006). Consumer Eroski. Recuperado el 6 de Mayo de 2009, de http://www.consumer.es/seguridad-alimentaria/ciencia-y-tecnologia/2006/10/11/25267. php

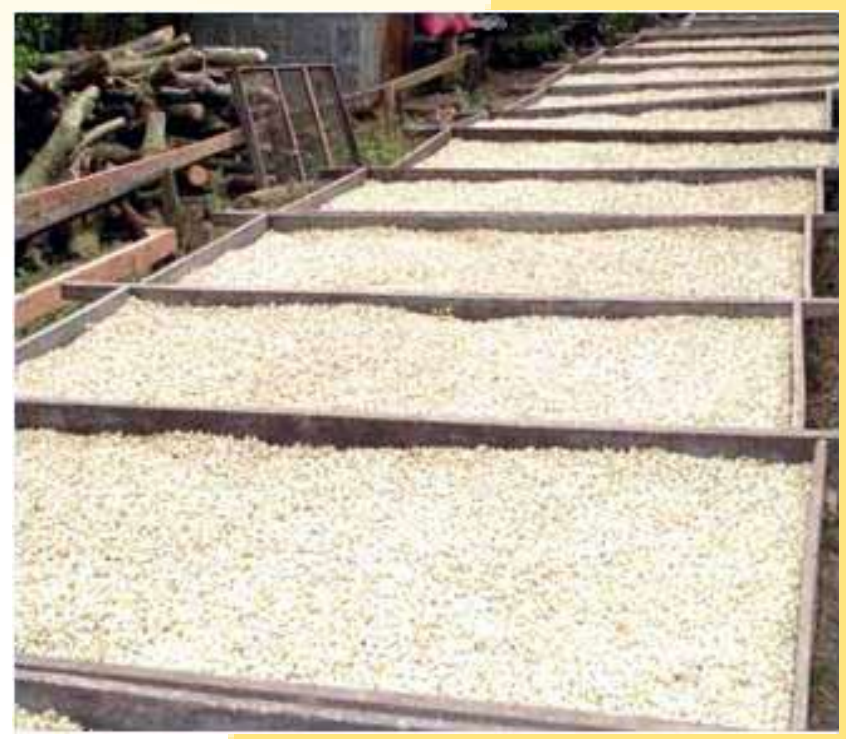

